\title{
Targeted Transduction of CNS Neurons with Adenoviral Vectors Carrying Neurotrophic Factor Genes Confers Neuroprotection That Exceeds the Transduced Population
}

\author{
Brian J. Baumgartner ${ }^{1}$ and H. David Shine ${ }^{1,2,3}$ \\ ${ }^{1}$ Department of Neurosurgery, ${ }^{2}$ Department of Cell Biology, and ${ }^{3}$ Division of Neuroscience, Baylor College of Medicine, \\ Houston, Texas 77030
}

\begin{abstract}
Application of neurotrophic factors (NFs) to the cut stump of motor nerves of neonatal rats confers neuroprotection from trauma-induced neuronal death. To test whether motoneurons are capable of responding to endogenously produced NFs, facial motoneurons were genetically modified in vivo to express several NFs and then tested for their response to peripheral nerve damage. Replication-defective adenoviral vectors [Adv.Rous sarcoma virus (RSV)-nf] representing three families of NFs were constructed that carried genes for brain-derived neurotrophic factor (BDNF), ciliary neurotrophic factor (CNTF), glial cell-derived neurotrophic factor (GDNF), and nerve growth factor. Media from cultured cells transduced with Adv.RSV-nf contained NFs that supported the survival of cultured chick sensory neurons in the same manner as recombinant NF standards. When Adv.RSV-nf or an adenoviral vector containing the $\beta$-galactosidase gene (Adv.RSV- $\beta$-gal) were injected into the facial muscles of neonatal rats the vectors were retrogradely
\end{abstract}

transported to the facial nucleus where the NFs or $\beta$-gal were expressed. A fraction $(\sim 10 \%)$ of the neurons were transduced as demonstrated by reverse transcriptase-PCR, histochemistry, and immunocytochemistry. In the case of Adv.RSV-BDNF, Adv.RSV-CNTF, and Adv.RSV-GDNF, a significant portion of the facial nucleus neurons was protected, $16.5,18.2$, and $53.3 \%$, respectively, from death after axotomy, showing that neurons are capable of transporting the Adv.RSV-nf, expressing the recombinant NF genes, and responding to the NFs. In the case of Adv.RSV-GDNF, a greater number of facial nucleus motoneurons survived than were transduced, indicating that neighboring untransduced neurons were protected by the GDNF expressed by the transduced neurons by a paracrine mechanism.

Key words: neurotrophic factors; neuroprotection; adenoviral vector; facial nerve; facial nucleus; nervous system trauma; retrograde transport
A number of biologically active molecules, collectively called neurotrophic factors (NFs), promote neuronal survival through receptor-mediated processes and are thought to be involved in nervous system development, maintenance, and response to trauma. Ciliary neurotrophic factor (CNTF), a member of the neuropoietin family, brain-derived neurotrophic factor (BDNF), a member of the neurotrophin family, and glial cell line-derived neurotrophic factor (GDNF), a member of the Transforming Growth Factor $\beta$ (TGF- $\beta$ ) family, all have demonstrable neuronal survival activity in vivo. Application of any one of these NFs to the proximal stump of a cut facial nerve or sciatic nerve of a neonatal rat protects the facial nucleus and spinal cord motoneurons, respectively, from axotomy-induced death (Sendtner et al., 1990, 1992; Yan et al., 1992; Koliatsos et al., 1993; Henderson et al., 1994; Friedman et al., 1995; Li et al., 1995). Under other conditions neurons may be stimulated by target-derived NFs to themselves express NFs that may, in turn, act both in an autocrine/paracrine manner (Schecterson and Bothwell, 1992). This

Received March 5, 1997; revised May 1, 1997; accepted June 10, 1997.

We thank Dr. R. Grossman for support and critical review of the manuscript; Ms. M. Docker, Dr. Z. S. Guo, Dr. J. Noebels, Dr. B. O'Malley, and Dr. S. L. C. Woo for their review of this manuscript; Dr. C. Contant for review of the statistical analysis; Ms. C. Cho, Ms. H. Collier, Ms. M. Docker, Mr. C. Hall, Mr. G. Louie, and Ms. N. Nash for their expert technical assistance in preparing vector and histological analysis; Dr. S. Whittemore for the NGF cDNA clone; and Dr. S. L. C. Woo and Dr. B. Fang for the pAdL.1/RSV plasmid.

Correspondence should be addressed to Dr. H. David Shine, Department of Neurosurgery, Baylor College of Medicine, 6560 Fannin Street, Suite 944, Houston, TX 77030.

Copyright (C) 1997 Society for Neuroscience $\quad 0270-6474 / 97 / 176504-08 \$ 05.00 / 0$ could amplify the neurotrophic effect of the retrogradely transported factors. If neurons are capable of producing and responding to NFs in an autocrine/paracrine manner, then genetically modifying them to produce and release NFs through the normal secretory pathway would protect them from axotomy-induced death as well as protecting their neighboring unmodified neurons. To test this postulate we genetically modified the target facial nucleus motoneurons with replication-defective adenoviral vectors carrying NF genes and determined whether neuronalexpressed NFs would result in protection from axotomy-induced neuronal death in the same manner as exogeneously applied NFs. Adenoviral vectors are retrogradely transported by axons and will transduce postmitotic neurons (Akli et al., 1993; Davidson et al., 1993; Le Gal La Salle et al., 1993; Neve, 1993). The adenoviral vectors carried NF genes representing neuropoietin, neurotrophin, and TGF- $\beta$ gene families and were shown to direct the expression of biologically active NFs in mammalian cells in vitro. The property of axonal transport of adenoviral vectors made it possible to introduce the NFs to their neuronal targets where they were expressed. Hence, it was possible to transduce facial nucleus neurons in the CNS by injecting the vectors in the facial muscles. This left the CNS intact by avoiding physical trauma to the region of the target neurons and inflammation caused by the direct introduction of vector particles. Neuronal survival over control values would suggest that neurons can express NFs and can respond to the NFs in an autocrine manner. A survival greater than the number of transduced neurons would indicate that 
neighboring untransduced neurons are capable of responding to NFs produced by transduced neurons in a paracrine manner.

\section{MATERIALS AND METHODS}

Preparation of adenoviral vectors carrying genes for NFs. Total RNA was extracted from cells or tissues using the procedure of Chomczynski and Sacchi (1987). Total RNA from rat sciatic nerve or adult rat brain was used to synthesize CNTF cDNA or BDNF cDNA, respectively. RNA from the astrocytoma cell line $\mathrm{C}_{6}$ was used to generate GDNF cDNA Reverse transcriptase-PCR (RT-PCR) analysis was performed as described elsewhere (Baumgartner and Barnes, 1994). First-strand cDNA was synthesized from total RNA using avian myeloblastosis virus $(\mathrm{AMV}) \mathrm{RT}$ and an oligo-dT primer (CNTF and BDNF) or the specific PCR reverse primer (GDNF). Specific oligonucleotide primers (Genosys, The Woodlands, TX) for PCR were designed using the nucleotide sequences of rat CNTF (forward, 5'-ATAAAGCTTTTAGGGGATGGCTTTCGCAG-3'; reverse, 5'-TATTCTAGACTACATCTGCTTATCTTTGGC-3'), BDNF (forward, 5'-ATAAAGCTTAGAGTGATGACCATCCTTTTCC-3'; reverse, 5'-TATTCTAGACTATCTTCCCCTTTTAATGGTC $-3^{\prime}$ ), and GDNF (forward, 5'-ATAAAGCTTGGACGGGACTCTAAGATGAAG-3'; reverse, 5'-ATATCTAGATCAGATACATCCACACCGTT-3'). The forward primers spanned the Kozak translation initiation sequence and the first two to three codons. The reverse primers corresponded to the final six to seven codons, including the translation termination codon. Nucleotide sequences encoding the HindIII (forward primer) or $\mathrm{XbaI}$ (reverse primer) restriction endonuclease cleavage sites (shown in italics) were added to the $5^{\prime}$ ends to facilitate cloning. Additional primers used in this study included the Rous sarcoma virus (RSV)-long terminal repeat (LTR) forward primer (5'-CCACATTGGTGTGCACCTCC-3'), the NGF reverse primer (5'TCAGCCTCTTCTTGCAGCCT- $\left.3^{\prime}\right)$, and a BDNF reverse primer $\left(5^{\prime}-\right.$ TACTGTCACACACGCTCAGC-3'). Agarose electrophoresis showed that single cDNA fragments of the expected size were obtained from each primer set after PCR, which were then cloned into the plasmid pAdL.1/RSV (Fang et al., 1994). The plasmid pADL.1/RSV (kindly provided by B. Fang and S. L. C. Woo, Baylor College of Medicine, Houston, TX) contains a multiple cloning site (MCS) for inserting DNA fragments, which is flanked on the $5^{\prime}$ end by the RSV-LTR promoter and contains the polyadenylation $[\operatorname{poly}(\mathrm{A})]$ sequence from the bovine growth hormone $(\mathrm{BGH})$ gene at the $3^{\prime}$ end. The RSV-LTR promoter, MCS, and $\mathrm{BGH}$ poly(A) site are flanked by adenovirus (Adv) DNA sequences from the "left" end of the adenoviral genome. DNA sequence analysis of the resultant recombinant plasmids was performed using the Sequenase II kit (United States Biochemicals, Cleveland, $\mathrm{OH}$ ) and showed $100 \%$ identity to the published sequences. NGF cDNA (from pBluescribe/NGF, kindly provided by S. Whittemore, University of Miami School of Medicine, Miami, FL) was also subcloned into pADL.1/RSV. Others have shown that the RSV promoter functions in neuronal cells (Akli et al., 1993; Le Gal La Salle et al., 1993; Finiels et al., 1995). The methods of Graham and Prevec (1991) were used to construct replication-defective recombinant Adv vectors via homologous recombination using the plasmid pJM17 (which contains the E1A-deleted Adv type 5 genome). The recombinant pADL.1/RSV plasmid containing the neural growth factor cDNAs (pADL.1/RSV-nf) were co-transfected with pJM17 into HEK293 cells, and plaques (consisting of recombinant Adv vectors) were allowed to develop over 2 weeks. PCR with the specific cDNA reverse primer and the RSV-LTR vector forward primer was used to confirm that the resultant Adv.RSV- $n f$ vectors contained the correct NF gene construct. Adv.RSV- $n f$ vectors were purified by two rounds of "plaque purification" using PCR to confirm that the plaques contained the appropriate NF sequences. Large scale production and $\mathrm{CsCl}$ purification of the Adv.RSV- $n f$ vectors was performed as described by Graham and Prevec (1991), and the viral titer was determined by plaque assay.

Western blot analysis of NFs expressed by HeLa cells transduced with $A d v \cdot R S V$-nf in vitro. HeLa cells were transduced with the Adv.RSV-nf vectors at an appropriate multiplicity of infection (MOI; usually 100) to obtain a high degree of transduction without viral-induced cytopathic effect. The medium was replaced after $16 \mathrm{hr}$ with serum-free DMEM and further incubated for $56 \mathrm{hr}$. The serum-free medium $(100-500 \mu \mathrm{l})$ was concentrated 10 -fold with 3000 molecular weight cutoff SpinX-UF3 centrif uge filters (Costar, Cambridge, MA). For expression of CNTF, HeLa cells were transfected as above. After $72 \mathrm{hr}$, the cells were harvested into HBSS and freeze-thawed. The extracts were centrifuged to remove cellular debris, and the supernatant was used as the source of CNTF. Control cells were transduced with an adenoviral vector carrying the gene for $\beta$-galactosidase (Adv.RSV- $\beta$-gal). The concentrated conditioned medium or HeLa cell extracts (for Adv.RSV-CNTF-transduced cells) were electrophoresed on $15 \%$ polyacrylamide gels (Laemmli, 1970) and electrophoretically transferred to nitrocellulose filters (Towbin et al., 1979). Commercially obtained NFs were included as standards. NFs were identified on the nitrocellulose filters using commercially obtained antibodies to NGF, BDNF, and GDNF (Santa Cruz Biotechnology, Santa Cruz, CA; and Promega, Madison, WI), and anti-CNTF was provided by H.D.S. (Rabinovsky et al., 1992). Antibodies to NGF, BDNF, and GDNF were shown to be specific for their respective neurotrophic factors by the manufacturers with no detectable crossreaction with the other factors. Detection of the immobilized antibodies was performed with anti-rabbit IgG-alkaline phosphatase (anti-CNTF, anti-BDNF, and anti-GDNF), whereas anti-rabbit IgG-horseradish peroxidase (HRP) was used for anti-NGF. The nitro blue tetrazolium-5bromo-1-chloro-3-indolyl phosphate substrate was used for color detection by the IgG-alkaline phosphatase conjugates, whereas the ECL kit (Amersham, Arlington Heights, IL) was used for the IgG-HRP conjugate. To determine whether conditioned medium from HeLa cells transduced with Adv.RSV-GDNF contained glycosylated forms of GDNF, it was digested with endoglycosidase $\mathrm{F}$ and $\mathrm{N}$-glycosidase F. Serum-free medium was lyophilized and resuspended in 1\% SDS and boiled for 2 min. The solution was cooled, added to a reaction buffer solution to give a final concentration of $10 \mathrm{~mm}$ phosphate buffer, $\mathrm{pH} 7.5,1 \mathrm{~mm}$ EDTA, and $0.5 \% n$-octylglucoside and boiled for $2 \mathrm{~min}$. After cooling, $1 \mathrm{U}$ each of endoglycosidase $\mathrm{F}$ and $\mathrm{N}$-glycosidase F (Boehringer Mannheim, Indianapolis, IN) was added to the mixture, and it was incubated for $12 \mathrm{hr}$ at $37^{\circ} \mathrm{C}$. The digested sample was analyzed by Western blot analysis as described above and compared with undigested conditioned medium and an unglycosylated recombinant GDNF standard.

Determination of NF synthesis rates from Adv.RSV-nf-transduced HeLa cells in vitro by ELISA. The concentration of NGF in the culture medium of cells transduced with Adv.RSV-NGF or the concentration of CNTF in Adv.RSV-CNTF-transduced cells was measured using quantitative ELISAs from Boehringer Mannheim. GDNF levels were measured using the GDNF ELISA from Promega (Madison, WI). BDNF concentration was determined as described by Eaton and Whittemore (1996). The appropriate recombinant NF was used to generate a standard curve for each ELISA.

Analysis of biological activity of conditioned medium from HeLa cells transduced with Adv.RSV-nf on chick sensory neurons. HeLa cells were transduced with the Adv.RSV-nf vectors at an MOI of 100 and incubated for $48 \mathrm{hr}$, after which the medium was replaced. After $24 \mathrm{hr}$ the conditioned medium was collected (except for HeLa cells that were transduced with Adv.RSV-CNTF, which were harvested in HBSS after $72 \mathrm{hr}$ as described above for Western blotting) and was analyzed for NF activity in sensory neuron cultures. Primary cultures of dissociated E10 chick embryo dorsal root ganglia (DRGs) or E6 nodose ganglia (NGs) were grown in DMEM with $10 \%$ fetal bovine serum that was supplemented with commercial recombinant NFs at $100 \mathrm{ng} / \mathrm{ml}$ for BDNF, GDNF, and $\mathrm{NGF}, 10 \mathrm{ng} / \mathrm{ml}$ for CNTF, $25 \%$ (v/v) for the conditioned medium, or 100 $\mu \mathrm{g}$ of extract from Adv.RSV-CNTF-transduced cells. DRG and NG neurons were also cultured with combinations of Adv.RSV-nf conditioned media in which the conditioned media (or $100 \mu \mathrm{g}$ of Adv.RSVCNTF cell extract) were mixed to give a total concentration of $25 \%(\mathrm{v} / \mathrm{v})$ with DMEM. Dissection of ganglia and neuronal cell culture was as described elsewhere (Davies, 1989). The number of surviving neurons per culture well was determined by counting cresyl violet-stained neurons at $100 \times$ magnification in 10 fields and then computing the total number for each well in each of two or three wells in NG or DRG cultures, respectively. Treatment effect on survival was analyzed using ANOVA followed by Bonferroni's test. Analysis of DRG survival was repeated five times, and analysis of NG survival was repeated three times with the same results.

Determination of transduction rate of facial nucleus neurons after Adv.RSV$\beta$-gal injection in the facial muscles. Experiments and care of animals were performed in accordance with approved protocols of Baylor College of Medicine and under biosafety level 2 guidelines. A total of $10 \mu \mathrm{l}$ of Adv.RSV- $\beta$-gal $\left(1.9 \times 10^{8} \mathrm{pfu}\right)$ was injected into the left facial muscles of the cheek, lower lip, and whisker pad of newborn Sprague Dawley rats (Harlan, Houston, TX; $n=4$ ) anesthetized with hypothermia. Seven days later they were anesthetized with halothane and perfused intracardially with heparinized PBS, $\mathrm{pH} 7.4$, and then $4 \%$ paraformaldehyde in PBS. The brains were removed, postfixed overnight in paraformaldehyde, cryoprotected in $21 \%$ sucrose, embedded in O.C.T. (Tissue-Tek; Miles, Elkhart, IN), and frozen. The facial nucleus region was sectioned at $40 \mu \mathrm{m}$ with a 
cryostat and washed in PBS. The sections were reacted for $\beta$-galactosidase activity by incubating them for $1-2 \mathrm{hr}$ at $37^{\circ} \mathrm{C}$ in a solution containing 0.5 $\mathrm{mg} / \mathrm{ml}$ 5-bromo-4-chloro-3-indolyl- $\beta$-D-galactoside (X-gal; Sigma, St. Louis, MO) in $44 \mathrm{~mm} \mathrm{HEPES} \mathrm{buffer,} \mathrm{pH} 7.4$, with $3 \mathrm{mM} \mathrm{K}_{3} \mathrm{Fe}(\mathrm{CN})_{6}, 3 \mathrm{~mm}$ $\mathrm{K}_{4} \mathrm{Fe}(\mathrm{CN})_{6}, 15 \mathrm{~mm} \mathrm{NaCl}$, and $1.3 \mathrm{mM} \mathrm{MgCl}_{2}$. The sections were washed in PBS, mounted on gelatin-coated slides, and counterstained with cresyl violet. $\beta$-Galactosidase-positive neurons in the treated facial nucleus and untransduced neurons in both left and right facial nuclei were counted.

Analysis of neuroprotective activity in neonatal rat facial nucleus motoneurons after facial nerve trauma. Adv.RSV-nf or Adv.RSV- $\beta$-gal (10 $\mu l)$ was injected into the left facial muscles as described above. The maximum amount of virus obtainable in a $10 \mu \mathrm{l}$ volume was used. After $2 \mathrm{~d}$ the pups were anesthetized as above, the facial nerve was severed, and a $5 \mathrm{~mm}$ segment was removed (including the auricular branch) from $\sim 1$ $\mathrm{mm}$ distal to the stylomastoid foramen. Seven days later they were anesthetized with halothane and perfused intracardially with heparinized PBS followed by $4 \%$ paraformaldehyde in PBS, and the brains removed and embedded in paraffin. Coronal sections $(10 \mu \mathrm{m})$ were taken through the full extent of the facial nucleus and stained with cresyl violet, and the neurons in both facial nuclei were counted. Neurons were only counted if they were $>20 \mu \mathrm{m}$ in diameter and their nucleoli were readily visible. In some experiments the brains were processed for immunocytochemical staining by fixing with Zamboni's fixative (4\% paraformaldehyde and $15 \%$ picric acid in $0.1 \mathrm{M}$ phosphate buffer) and sectioning at $40 \mu \mathrm{m}$ with a cryostat. CNTF was detected in the neurons of the facial nucleus by immunocytochemistry using an antiserum raised in rabbits to recombinant CNTF (Rabinovsky et al., 1992) and techniques described elsewhere (Smith et al., 1993).

$R T-P C R$ analysis of facial nuclei regions for the presence of NF $m R N A$. RT-PCR was used to detect expression of Adv.RSV- $n f$ in CNS tissues or tissues at the injection site. Seven days after Adv.RSV- $n f$ was injected into facial muscles the rat pups were killed, and the brains and facial muscles were collected. The regions of the brains containing the facial nuclei were isolated by sectioning the brainstem at the pontine-mesencephalic junction and the medullary-spinal cord junction and then dividing the medulla at the midline. RNA was extracted and treated with $2 \mathrm{U}$ of RQ1 DNase (RNase-free; Promega) for $30 \mathrm{~min}$ followed by phenol extraction. Firststrand cDNA was synthesized ( $20 \mu \mathrm{g} / \mathrm{ml}$ total RNA concentration) with AMV RT (Promega) and oligo-dT 12-18 primer. Negative control reactions included minus RT and minus RNA reactions; positive controls included RNA from Adv.RSV-nf-transduced HeLa cells, as well as the original shuttle plasmids (pADL.1/RSV- $n f$ ). cDNA from $200 \mathrm{ng}$ of RNA was used for PCR, which was cycled 35 times at $90^{\circ} \mathrm{C}$ for $60 \mathrm{sec}, 63^{\circ} \mathrm{C}$ for $30 \mathrm{sec}$, and $70^{\circ} \mathrm{C}$ for $1 \mathrm{~min}$. The RSV-LTR forward primer and the specific reverse primers were used in the PCR to detect the chimeric Adv.RSV-nf transcripts and thus would not amplify endogenous NF gene transcripts. PCR products were visualized by agarose electrophoresis.

\section{RESULTS}

\section{Expression of NFs by HeLa cells transduced with Adv.RSV-nf in vitro}

To verify that transduction with Adv.RSV-nf can cause cells to produce NFs, HeLa cells were transduced with the vectors, and the culture medium was collected $72 \mathrm{hr}$ later and analyzed by Western blot analysis using commercially available recombinant NFs as references. HeLa cells transduced with Adv.RSV- $n f$ produced proteins that co-migrated with the NF standards and cross-reacted with antibodies that were specific for each of the NF proteins (Fig. 1). Neither untransduced HeLa cells nor cells transduced with Adv.RSV- $\beta$-gal produced proteins that cross-reacted with the anti-NF antibodies (data not shown). In the case of GDNF, higher molecular weight cross-reacting species were present, indicating that the protein was post-translationally modified, presumably by glycosylation in a manner similar to the native protein (Lin et al., 1993). Endoglycosidase F and $N$-glycosidase F digestion of serumfree medium from HeLa cells transduced with Adv.RSV-GDNF almost completely eliminated the higher molecular weight bands and increased the density of the $15 \mathrm{kDa}$ band, verifying that these bands represented glycosylated forms of GDNF. An estimate of the amount of NF produced was obtained by using quantitative
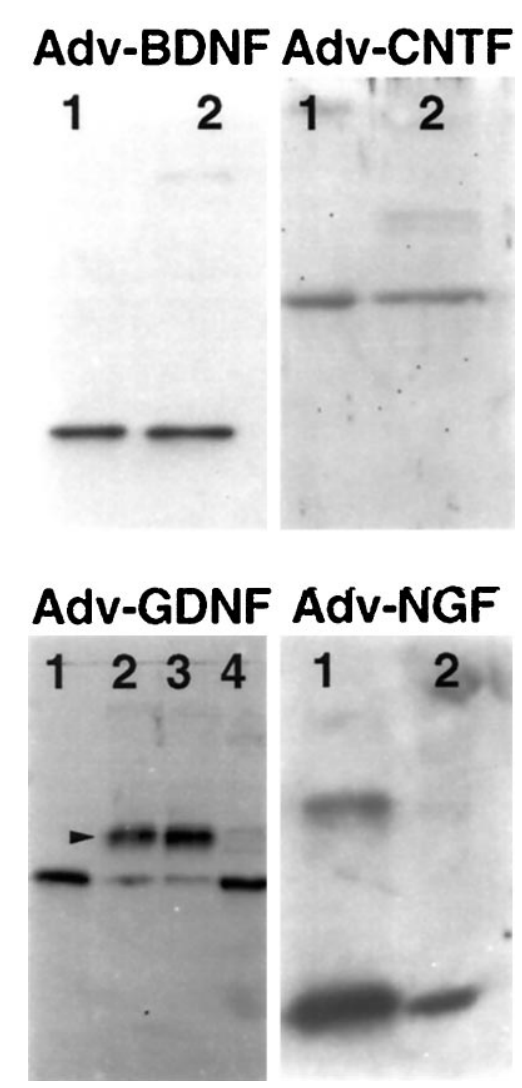

Figure 1. Expression of NFs by HeLa cells transduced with Adv.RSV- $n f$. Western blot analyses were performed on conditioned media or cell extracts from HeLa cells transduced with Adv.RSV-nf. The media and cell extract contained proteins that co-migrated (lanes 2) with the corresponding purified recombinant growth factors used as standards (lanes 1). The protein produced from cells transduced with Adv.RSV-GDNF showed cross-reacting bands (arrowhead) that migrated at higher apparent molecular weights than the unglycosylated standard. Glycosidase digestion of the conditioned medium from cells transduced with Adv.RSVGDNF converted most of the high molecular weight protein to the size of the GDNF standard (lane 4), indicating that the protein was glycosylated by the HeLa cells. (Lane 3 is Adv.RSV-GDNF conditioned medium incubated in glycosidase reaction buffer without the addition of glycosidase.) Neither untransduced HeLa cells nor cells transduced with Adv.RSV- $\beta$-gal produced proteins that cross-reacted with the anti-NF antibodies (not shown). Molecular weights for the monomeric forms of recombinant standards are: rat CNTF, $23 \mathrm{kDa}$; human BDNF, $14 \mathrm{kDa}$; human $\beta$-NGF, $14 \mathrm{kDa}$; and human GDNF, $15 \mathrm{kDa}$.

ELISAs. HeLa cells transduced with 100 active particles of Adv.RSV-NGF per cell produced $\beta$-NGF at a rate of $\sim 5 \mu \mathrm{g} \cdot 10^{6}$ cells $^{-1} \cdot \mathrm{d}^{-1}$. This compares favorably with estimates of $1 \mu \mathrm{g}$ of $\mathrm{NGF} \cdot 10^{6}$ cells $^{-1} \cdot \mathrm{d}^{-1}$ produced in cultured $3 \mathrm{~T} 3$ fibroblasts transduced with a herpes virus vector carrying the NGF cDNA (Geschwind et al., 1994). The rates of expression of BDNF, CNTF, and GDNF produced by HeLa cells transduced with $100 \mathrm{MOI}$ of the respective Adv.RSV- $n f$ were determined to be $63.6 \pm 22.3$ $\mathrm{ng} \cdot 10^{6}$ cells $^{-1} \cdot \mathrm{d}^{-1}, 0.54 \pm 0.19 \mu \mathrm{g} \cdot 10^{6}$ cells $^{-1} \cdot \mathrm{d}^{-1}$, and $11.3 \pm$ $2.5 \mathrm{ng} \cdot 10^{6}$ cells $^{-1} \cdot \mathrm{d}^{-1}$, respectively.

\section{Neuroprotection of cultured chick sensory neurons by media conditioned by cells transduced with Adv.RSV-nf}

The biological potency of the NFs produced by HeLa cells transduced with Adv.RSV- $n f$ was measured by culturing embryonic sensory neurons from dissociated chick NGs and DRGs in media 
from cultures of HeLa cells transduced with Adv.RSV- $n f$. The biological activities of the conditioned media were compared with the activities of conditioned medium from cells transduced with Adv.RSV- $\beta$-gal, conditioned medium from untransduced HeLa cells, and saturating amounts of commercial NFs. The conditioned media from HeLa cells that had been transduced with the Adv.RSV- $n f$ had significant $(p<0.05)$ survival effects on NG and DRG neurons compared with medium removed from cells transduced with Adv.RSV- $\beta$-gal, with the exception of medium from cells transduced with Adv.RSV-NGF when applied to NG cells (Fig. 2). Media from untransduced HeLa cells or HeLa cells transduced with Adv.RSV- $\beta$-gal provided a slight survival effect over nonconditioned medium alone. However, the survival effects were enhanced 2- to 11-fold in media from HeLa cells transduced with Adv.RSV-nf, suggesting that the survival effects seen in vitro were primarily attributable to NFs produced by the Adv.RSV- $n f$. The lack of an effect with Adv.RSV-NGF is not unexpected, because NG cells do not respond to NGF in vitro (Lindsay and Rohrer, 1986). Combining multiple neurotrophic factors produces an additive effect on neuronal survival in vitro. Combining conditioned media from HeLa cells transduced with Adv.RSV-BDNF and Adv.RSV-GDNF had an additive survival effect on NG cells, and combining conditioned media from cells transduced with Adv.RSV-BDNF and Adv.RSV-NGF with extracts of cells transduced with Adv.RSV-CNTF had an additive effect on DRG cells as well (Fig. 2). Because the final total concentrations of the conditioned media were held to $25 \%$, there was a lower concentration of each NF in the combined media. Nevertheless, greater neuronal survival was obtained with the combined media than from each conditioned medium alone, and this verifies that the Adv.RSV- $n f$-transduced HeLa cells are producing NFs. If neuronal survival was attributable to a factor produced by HeLa cells, the combined conditioned media from HeLa cells transduced with several different Adv.RSV- $n f$ would have no greater survival effect than conditioned medium from HeLa cells transduced with a single Adv.RSV-nf or untransduced HeLa cells.

\section{Retrograde transport of Adv.RSV- $\beta$-gal from facial muscles to facial nucleus neurons}

When Adv.RSV- $\beta$-gal was injected into the facial muscles of newborn rats, the vector was taken up and retrogradely transported to facial nucleus neurons where the $\beta$-galactosidase gene under RSV promoter control was expressed (Fig. 3). Trigeminal neurons were also positive for $\beta$-galactosidase, indicating that Adv.RSV- $\beta$-gal was taken up and retrogradely transported by trigeminal nerve axons (data not shown) as well. The percentage of facial nucleus neurons on the injected side that expressed $\beta$-galactosidase was $9.4 \pm 3.7 \%$ (mean $\pm \mathrm{SD} ; n=4)$. Within each tissue section the $\beta$-galactosidase-positive neurons tended to be grouped within the facial nucleus. We believe that these neurons preferentially innervated the muscles that were injected with Adv.RSV- $\beta$-gal, and thus their axons were more readily exposed to the vector. There was no significant $(p=0.73)$ difference between the total number of neurons in the left (injected) and right (uninjected) facial nuclei $(3922 \pm 406$ and $3769 \pm 756$ neurons, respectively; mean $\pm \mathrm{SD} ; n=4)$, indicating that at $7 \mathrm{~d}$ after injection there was no neuronal death caused by the vector or the $\beta$-galactosidase. No inflammation or other neuropathology was observed in facial nuclei on the injected side. In most cases the $\mathrm{X}$-gal reaction product was present in the nuclei of the neurons, because the $\beta$-galactosidase gene has a nuclear localiza-

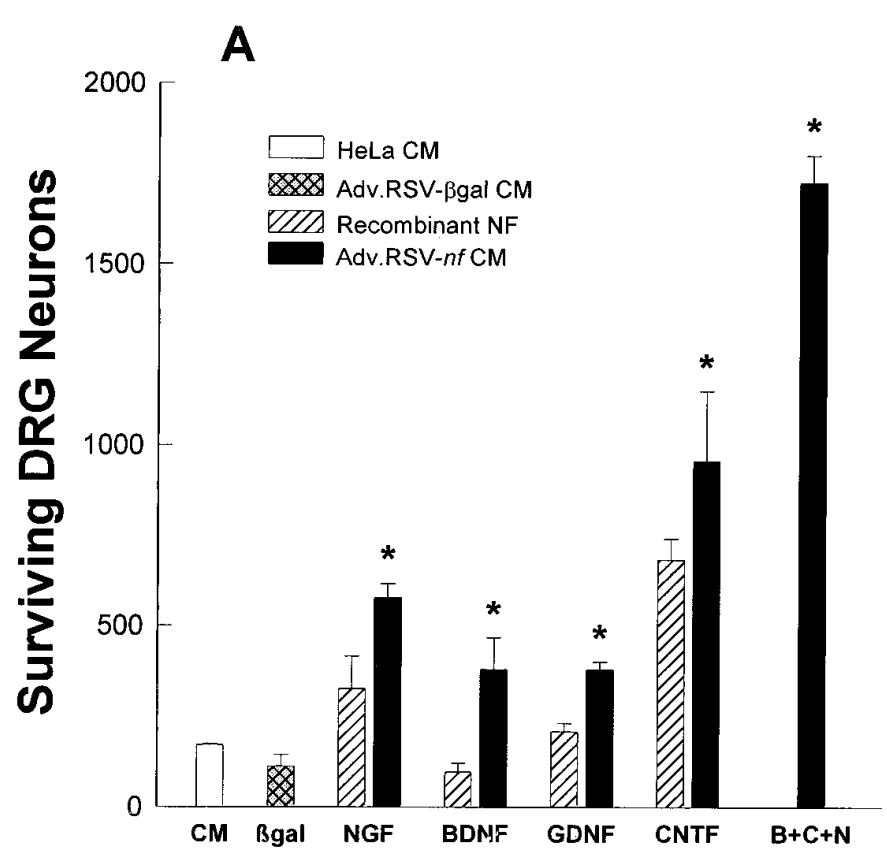

B

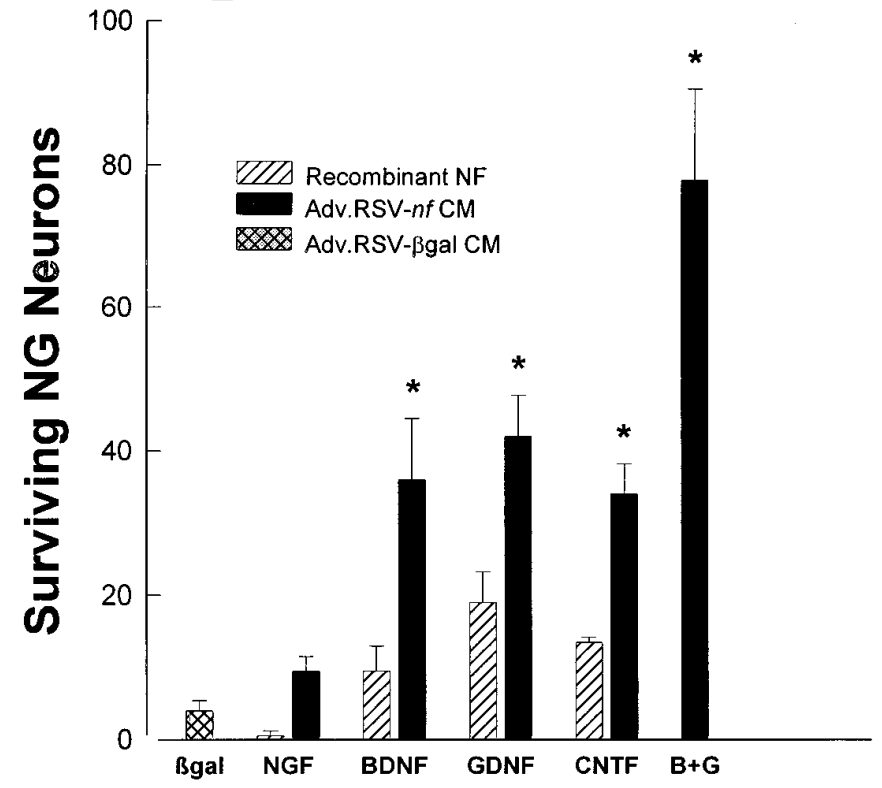

Figure 2. Biological activity of NFs produced by HeLa cells transduced with Adv.RSV-nf vectors in vitro. Primary cultures of dissociated DRG $(A)$ and NG $(B)$ cells from chick embryos were grown in media containing culture medium from untransduced HeLa cells (white bar), $25 \%$ (v/v) of conditioned medium from HeLa cells $(C M)$ transduced with Adv.RSV$\beta$-gal (cross-hatched gray bars), or Adv.RSV-nf (black bars). In the case of CNTF a crude extract of cells transduced with Adv.RSV-CNTF or Adv.RSV- $\beta$-gal was mixed with standard medium. Surviving neurons were counted after $48 \mathrm{hr}$. *Value significantly different $(p<0.05)$ from Adv.RSV- $\beta$-gal value by one-way ANOVA with Bonferroni's multiplecomparison test. Error bars indicate SD. $B+G$, BDNF and GDNF; $B+C+N, \mathrm{BDNF}, \mathrm{CNTF}$, and NGF. 


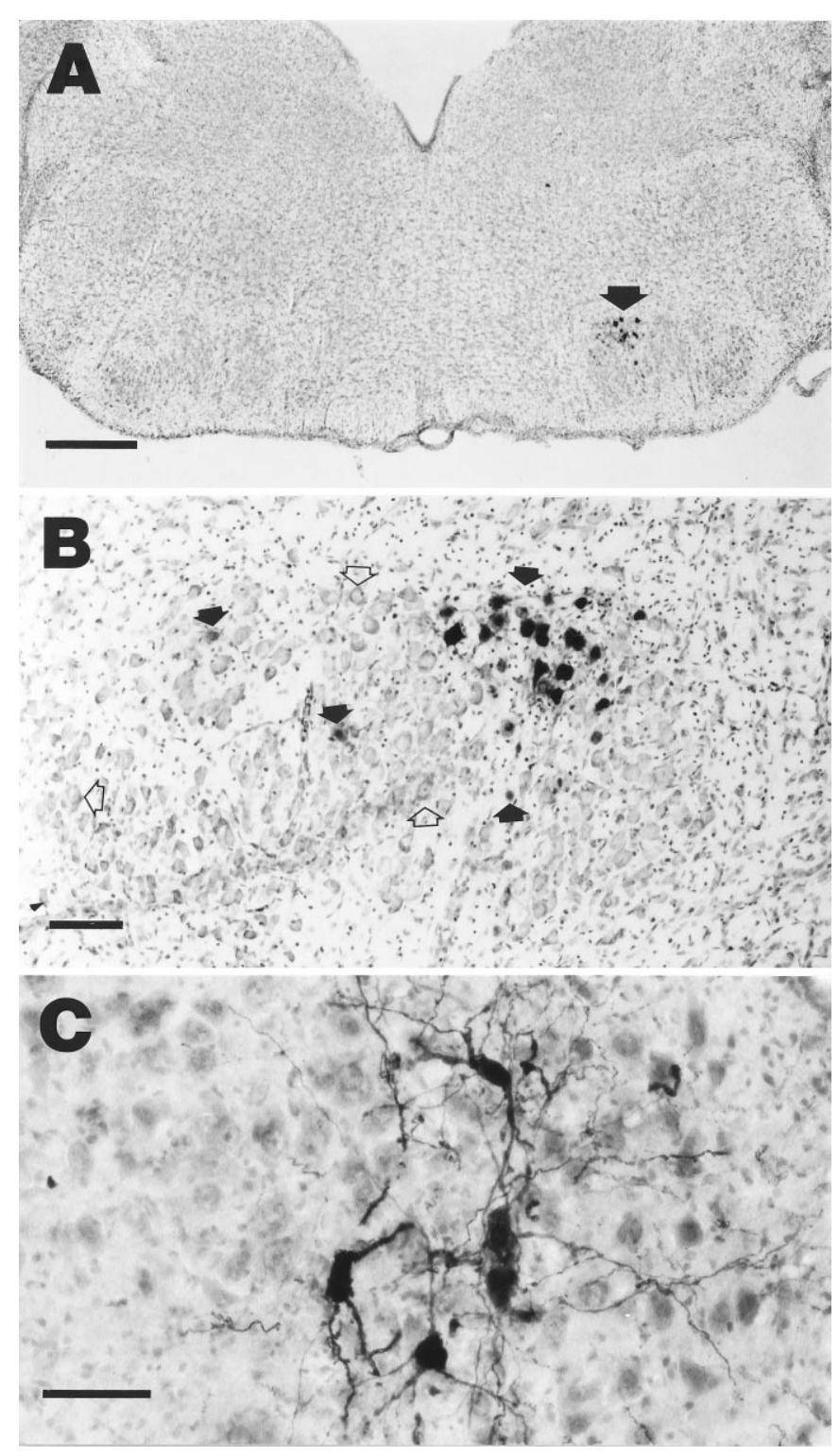

Figure 3. Retrograde transport and expression of Adv.RSV- $\beta$-gal and Adv.RSV-CNTF. $A, \beta$-Galactosidase-positive neurons in the facial nucleus (arrow) $7 \mathrm{~d}$ after injection of Adv.RSV- $\beta$-gal into facial muscles. Scale bar, $500 \mu \mathrm{m}$. $B$, Detail of facial nucleus of a different rat than in $A$ showing $\beta$-galactosidase-positive neurons (filled arrows) and nontransduced neurons (open arrows). Scale bar, $100 \mu \mathrm{m}$. C, Facial nucleus neurons that are immunopositive for CNTF in a field of nontransduced neurons stained with cresyl violet. Scale bar, $50 \mu \mathrm{m}$.

tion sequence, but in some cases the reaction product filled the whole neuron and delineated its processes (Fig. 3).

\section{Retrograde transport of Adv.RSV-nf, expression of NF genes, and neuroprotection of facial nucleus neurons from axotomy-induced death}

Protection against axotomy-induced neuronal death was tested by injecting Adv.RSV- $n f$ into the muscles of the terminal fields of the facial nerve of neonatal (1-d-old) rats. Control animals were injected with Adv.RSV- $\beta$-gal. Two days later the facial nerves on the injected side were cut. The neurons of the ipsilateral facial nuclei that survived $7 \mathrm{~d}$ after axotomy were counted, and their numbers were compared with the number of facial motoneurons of the unlesioned and untreated contralateral nuclei (Table 1). In control animals, $7 \mathrm{~d}$ after axotomy a large portion of the facial motoneurons on the cut side had disappeared, and the area of the facial nucleus was populated by cells with small nuclei, presumably astrocytes (Fig. 4). Injection of Adv.RSV-GDNF into facial muscles produced a robust survival effect (Table 1 ) on the lesioned facial nucleus neurons $(53.3 \% ; p<0.01)$ compared with the percentage of surviving neurons in animals treated with Adv.RSV- $\beta$-gal (7.9\%). Injection with Adv.RSV-CNTF and with Adv.RSV-BDNF each produced smaller but statistically significant $(p<0.05)$ survival effects compared with Adv.RSV- $\beta$-galtreated controls (18.2 and $16.5 \%$, respectively). Adv.RSV-NGF produced a small increase $(11.4 \%)$ of surviving neurons, which was not statistically significant and is in agreement with experiments in which NGF applied to cut facial nerves did not have neuroprotective activity (Koliatsos et al., 1993). The percentage of surviving facial nucleus neurons $(53 \%)$ in animals treated with Adv.RSV-GDNF was significantly $(p<0.0001)$ greater than the number of neurons $(9.4 \%)$ expected to be transduced based on injection with Adv.RSV- $\beta$-gal. There was no significant difference in the number of surviving neurons treated with the other Adv.RSV- $n f$ and the expected transduction rate of $9.4 \%$. There was no correlation between the relative neuronal survival and the plaque-forming units injected, as determined by Pearson's product-moment correlation test, and the numbers of contralateral neurons between groups were not significantly different by ANOVA.

\section{Detection of $\boldsymbol{n f}$ gene expression in vivo}

To confirm that the vectors were transported to and were expressed in the facial nuclei, RT-PCR was performed on RNA from tissue containing the ipsilateral facial nuclei, contralateral facial nuclei, and facial muscles $7 \mathrm{~d}$ after Adv.RSV- $n f$ injections using primers specific for mRNA transcribed from the vectors. The RT-PCR reactions were run in the presence or absence of RT to differentiate between signal from vector DNA and mRNA. Positive signal was detected only in the presence of RT for BDNF (two of three animals), CNTF (three of three animals), and GDNF (two of three animals) in RNA from tissue containing the ipsilateral facial nucleus (Fig. 5) but not the contralateral nucleus. For tissue from animals injected with Adv.RSV-NGF, PCR product was detected (one of three animals) in the presence and absence of RT but only in RNA from the ipsilateral tissues. RT-PCR was also performed on RNA from the facial muscles ipsilateral to the sites of injection. As expected, positive signal was obtained, showing the presence of Adv.RSV-nf mRNA from all four vectors in muscle cells at the injection site (data not shown).

For immunocytochemical detection of Adv.RSV-nf-mediated expression in the facial nucleus, Adv.RSV-CNTF was injected into the facial muscles of neonatal rats, and $7 \mathrm{~d}$ later the brains were removed and immunostained for CNTF. Intense reaction product was evident in the soma and processes of $\sim 5-10 \%$ of the facial nucleus neurons (Fig. 3), demonstrating the presence of elevated levels of CNTF protein in these cells. Our attempts to detect BDNF, GDNF, and NGF by immunocytochemistry using commercially available antibodies (Chemicon International, Temecula, CA) were unsuccessful. Measurement of NF levels in tissues containing Adv.RSV- $n f$-transduced facial nuclei neurons using commercially available ELISA kits for GDNF, NGF, and CNTF did not show concentrations of NFs greater than endogenous levels after $7 \mathrm{~d}$ (data not shown). 
Table 1. Neuroprotective activity of retrogradely transported Adv.RSV- $n \boldsymbol{f}$ to rat facial nuclei motoneurons

\begin{tabular}{|c|c|c|c|c|c|c|}
\hline Vector & pfu in $10 \mu \mathrm{l}$ & $\begin{array}{l}\text { No. of neurons } \\
\text { in ipsilateral } \\
\text { nucleus }( \pm S D)\end{array}$ & $\begin{array}{l}\text { No. of neurons } \\
\text { in contralateral } \\
\text { nucleus }( \pm S D)\end{array}$ & $\begin{array}{l}\text { Relative survival } \\
( \pm \mathrm{SD})\end{array}$ & $p(n f$ vs $\beta$-gal $)$ & $n$ \\
\hline Adv.RSV-GDNF & $3.0 \times 10^{8}$ & $1656 \pm 372$ & $3127 \pm 718$ & $0.53 \pm 0.06$ & $<0.01$ & 5 \\
\hline Adv.RSV-CNTF & $7.5 \times 10^{7}$ & $463 \pm 86$ & $2609 \pm 449$ & $0.18 \pm 0.04$ & $<0.05$ & 4 \\
\hline Adv.RSV-BDNF & $5.6 \times 10^{8}$ & $567 \pm 153$ & $3423 \pm 374$ & $0.16 \pm 0.04$ & $<0.05$ & 5 \\
\hline Adv.RSV-NGF & $2.9 \times 10^{8}$ & $460 \pm 243$ & $3926 \pm 1006$ & $0.11 \pm 0.05$ & NS & 3 \\
\hline Adv.RSV- $\beta$-gal & $1.9 \times 10^{8}$ & $254 \pm 165$ & $3454 \pm 254$ & $0.08 \pm 0.05$ & & 4 \\
\hline
\end{tabular}

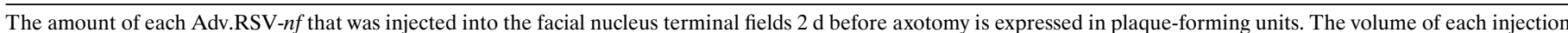

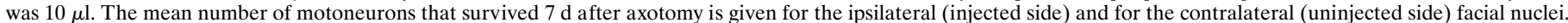

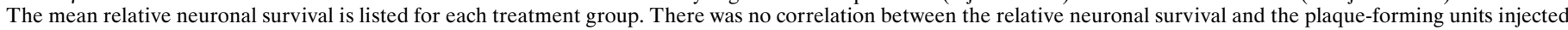

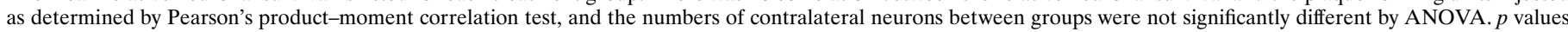

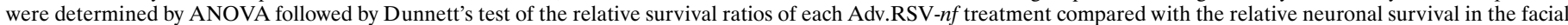
nuclei treated with Adv.RSV- $\beta$-gal. $n$, Animals in each treatment group.

\section{DISCUSSION}

These experiments demonstrate that (1) non-neuronal cells transduced with adenoviral vectors carrying NF genes will express biologically active NFs; (2) these vectors are retrogradely transported from peripheral nerve fields to the soma of CNS neurons where the recombinant genes are expressed; (3) the expressed NFs protect facial nucleus neurons from axotomy-induced death; and (4) a greater number of neurons are protected than the number that are transduced, indicating that the transduced neurons release the NFs that protect both themselves and their neighboring untransduced neurons.

\section{Mammalian cells transduced with Adv.RSV-nf produce authentic, biologically active NF proteins}

Western blot analysis of conditioned medium from HeLa cells transduced with Adv.RSV-nf showed that the cells produced proteins that were homologous to recombinant NF standards. In the case of Adv.RSV-GDNF-transduced HeLa cells, digestion of conditioned medium with glycosidases confirmed that they produced GDNF that was glycosylated, as is native GDNF (Lin et al., 1993). The amount of NFs produced by Adv.RSV- $n f$ transduced HeLa cells as estimated by ELISA was different for each Adv.RSV-nf vector. A number of explanations for this variability are possible. Because the vector backbones and RSV promoter were identical for each construct, a difference in expression rate must be a function of differences in post-transcriptional characteristics of each NF in the host cell. These differences may include the rate of post-translational modification, secretion, intracellular degradation, and the half-lives of NFs in the tissue culture medium. Additionally, it is possible that because antibodies used in these assays were produced against recombinant NFs produced in Escherichia coli, they may have different specificities to NFs produced by mammalian cells. For instance, posttranslational modification may modify or hide epitopes that are present on unmodified proteins.

Conditioned medium from HeLa cells transduced with Adv.RSV-nf vectors had significant survival effects on NG and DRG neurons in vitro compared with medium from untransduced HeLa cells or HeLa cells transduced with Adv.RSV- $\beta$-gal. This verified that the NF proteins were biologically active. The observation that a mixture of conditioned media from cells transduced with Adv.RSV-nf had an additive effect on chick sensory neurons (Fig. 2) is consistent with the findings of others (Kato and Lindsay, 1994).

Conditioned media from HeLa cells transduced with Adv.RSV-nf had greater survival effects than medium supple- mented with recombinant NFs obtained from commercial sources. These elevated biological activities may result from one or more factors, including survival factors produced by the HeLa cells that have additive effects with the adenovirally produced NFs, post-translational modification by the mammalian host cells that increase the specific activity of the NFs compared with NFs produced by prokaryotic systems, or that the commercial NFs had less than optimal biological activities.

\section{Adv.RSV-nf is retrogradely transported from terminal fields to CNS soma where the $n f$ genes are expressed}

Histochemical localization of $\beta$-galactosidase activity in facial nucleus neurons verified that the Adv.RSV- $\beta$-gal vector was retrogradely transported and expressed in facial nucleus motoneurons and was consistent with the observation of others (Finiels et al., 1995; Ghadge et al., 1995). RT-PCR analysis of the region containing the facial nucleus with primers specific for products of the vector constructs verified that Adv.RSV- $n f$ was transported from the injection sites to neurons in the ipsilateral facial nucleus where the recombinant genes were expressed. The lack of positive signal in the region of the contralateral facial nuclei indicates that the vector did not enter the brain by a systemic route. The low proportion of positive RT-PCR signal from RNA in animals injected with Adv.RSV-NGF compared with the other vectors may reflect poor PCR amplification efficiency of the cDNA, inefficient transport of the vectors, poor expression of the genes, transcriptional down-regulation, or rapid degradation of the mRNA. However, because all of the vectors were constructed from an identical viral backbone and were under control of an RSV promoter, it is more likely that inefficient PCR and/or rapid degradation of the transcripts may explain the results obtained with the Adv.RSV-NGF vector. Immunocytochemical localization of CNTF in facial nuclei neurons of animals transduced with Adv.RSV-CNTF verified that a mammalian gene for a neurotrophic factor under RSV control was expressed and confirms that the NF mRNAs are translated. We believe that our lack of success localizing these NFs other than CNTF by immunocytochemistry is a reflection of the difficulty of using this technique to localize NFs in neural tissue (Zhou et al., 1994). It is likely that CNTF was detected by immunocytochemistry, because it does not have a signal peptide, so the protein remained sequestered in the soma, unlike the other NFs that were probably rapidly secreted. Based on the positive detection of BDNF, GDNF, and NGF mRNAs in the region of the facial nucleus by RT-PCR and the measurable neuroprotective effect of facial nucleus motoneu- 


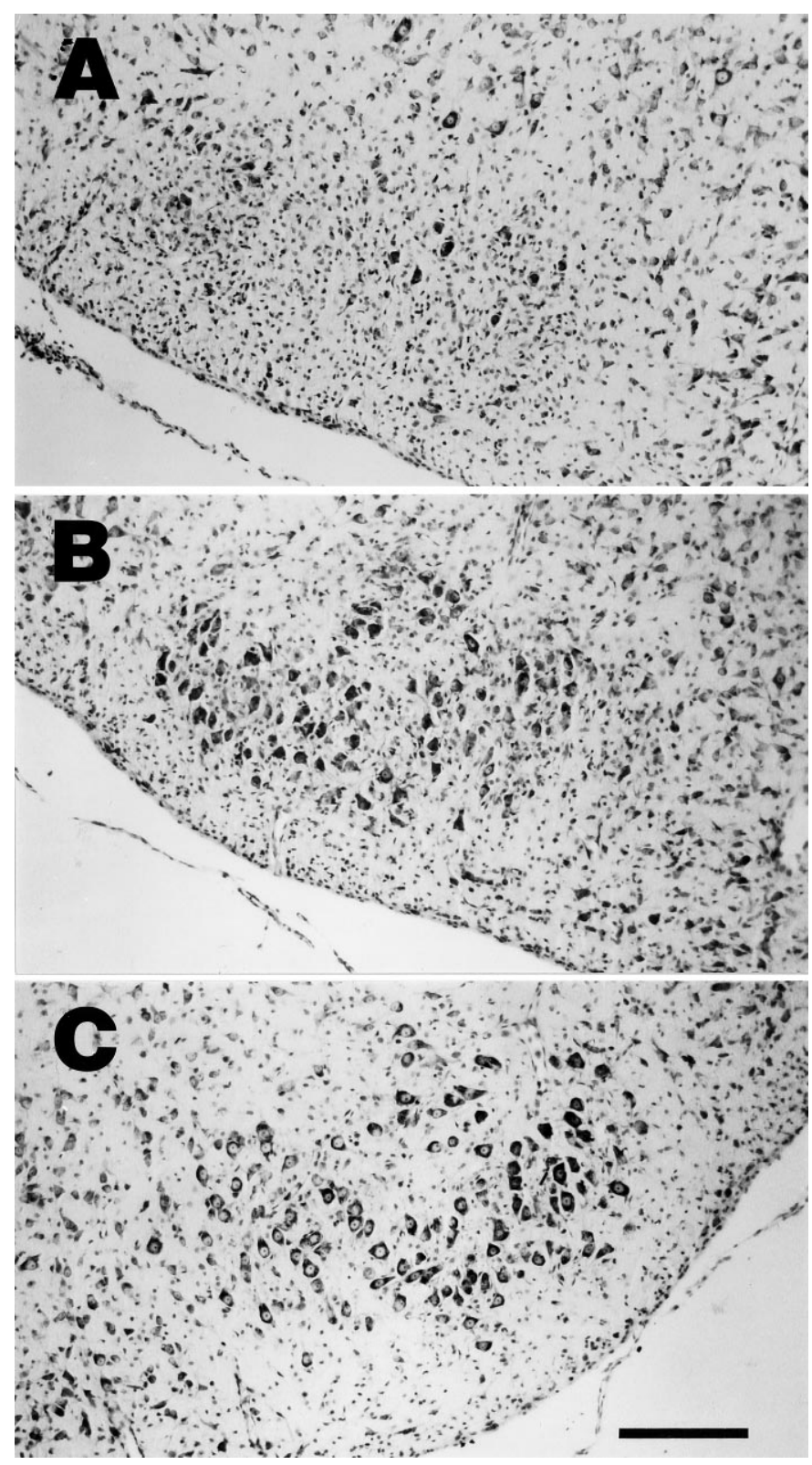

Figure 4. Protective effect of Adv.RSV-nf on axotomized facial nucleus neurons. Photomicrographs of cross-sections through the facial nucleus $9 \mathrm{~d}$ after injection of the ipsilateral facial muscles with Adv.RSV- $\beta$-gal $(A)$ and Adv.RSV-GDNF $(B)$ and $7 \mathrm{~d}$ after facial nerve transection. $C, \mathrm{~A}$ typical nucleus contralateral to the side injected. Scale bar, $200 \mu \mathrm{m}$.

rons by Adv.RSV-nf, it is reasonable to conclude that biologically active NF was produced in neurons transduced by all vectors.

\section{NFs expressed by transduced CNS neurons protect against axotomy-induced death}

The in vivo experiments showed that the neurons of the facial nucleus retrogradely transported Adv.RSV- $n f$ vectors, expressed the gene products, and, in turn, were protected from injury-induced death through an autocrine/paracrine mechanism. Although similar amounts of vector were injected into each treatment group, the neuroprotective effects of the Adv.RSV- $n f$ varied. Most likely this variability was attributable to the differences in the response of facial motoneurons to each NF. For instance, in vitro measurements show that GDNF is 75 - and 650 -fold more potent than

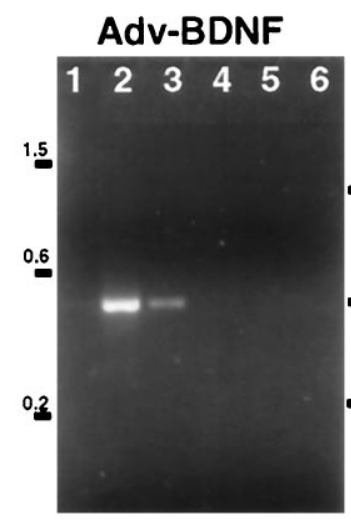

\section{Adv-CNTF}
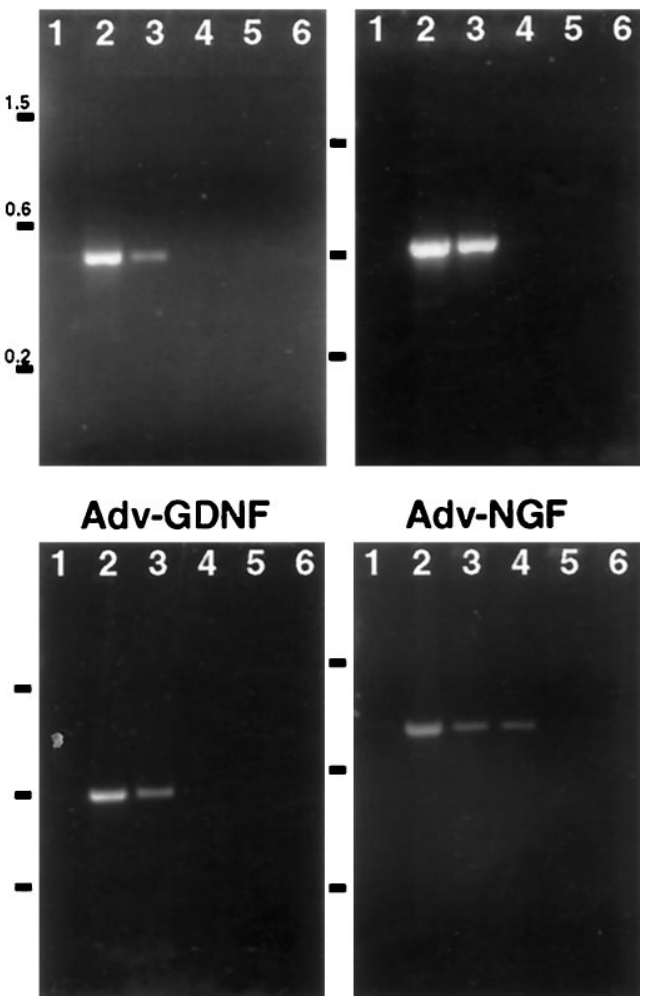

Adv-NGF

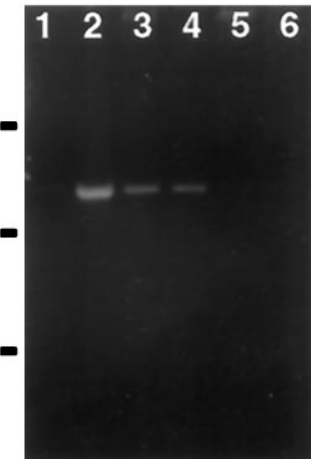

Figure 5. Detection of NF mRNA in regions of the facial nucleus after retrograde transport of Adv.RSV-nf. Adv.RSV-nf was injected into the facial muscles of neonatal rats, and total RNA was extracted from brainstem tissue after $7 \mathrm{~d}$ and analyzed by RT-PCR. Lane 1, No RNA; lane 2, positive control plasmid; lanes 3, 4, ipsilateral; lanes 5, 6, contralateral; lanes 3, 5; plus RT; lanes 4, 6, minus RT. Numbers to the left indicate sizes of markers in kilobase pairs.

BDNF and CNTF, respectively, in supporting the survival of purified embryonic rat spinal motoneurons (Henderson et al., 1994), which would be expected to be similar in NF dependence to facial nerve motoneurons. The observation that $53 \%$ of the neurons were protected at 1 week after axotomy when only $\sim 10 \%$ were transduced (based on Adv.RSV- $\beta$-gal transduction data) suggests that neighboring neurons responded to secreted GDNF through a paracrine mechanism.

The rate of survival of facial neurons in these experiments was not as high as reported in experiments in which recombinant NFs were used. When BDNF, CNTF, and GDNF were applied directly to the proximal stump of a severed facial nerve, they protected 80,76 , and $92 \%$, respectively, of the facial nucleus motoneurons (Sendtner et al., 1990; Koliatsos et al., 1993; Henderson et al., 1994). The difference between our observations and those using recombinant NFs may in part be attributable to the amounts of NFs that were available to the axotomized facial nucleus neurons. In experiments in which purified NFs were applied to the nerve stump, $5 \mu \mathrm{g}$ of CNTF (Sendtner et al., 1990), $15 \mu \mathrm{g}$ of BDNF (Koliatsos et al., 1993), and $20 \mu \mathrm{g}$ of GDNF (Henderson et al., 1994) were used. Based on our histochemical estimates of the expression of Adv.RSV- $\beta$-gal and Adv.RSV$\mathrm{CNTF}$, only $\sim 10 \%$ of the facial nucleus neurons expressed the recombinant proteins. This transduction efficiency and the estimated in vitro expression rates suggest that the total concentrations of NFs in the facial nuclei after Adv.RSV- $n f$ treatment were 
much lower than what was potentially available in experiments in which the NFs were applied directly to the cut axons.

\section{Adenoviral vector delivery of NFs may have potential for the treatment of neurological disorders}

The capacity of motoneurons to both express and respond to endogenous NF genes, coupled with the ability to modify the CNS genetically with adenoviral vectors administered peripherally, suggests that this may be a useful strategy in the treatment of neurodegenerative disorders and trauma. Although NFs may have applications in the therapy for trauma and neurodegenerative disease (Springer, 1993), their clinical use has been constrained by the difficulty of delivering the NFs to target neurons by systemic administration or direct inf usion. The short half-life of NFs and the lack of secondary modifications of bacteriaderived recombinant NFs may limit their biological activity and may require administration of large amounts of NFs to reach an effective therapeutic concentration at the target site. High systemic concentrations of NFs may enable them to act on cells other than the intended targets, thereby causing unwanted side effects. Directly targeting the sites in the CNS through retrograde transport of gene vectors may avoid problems associated with systemic delivery of therapeutic proteins and at the same time may enable the delivery of a protein that may have greater biological efficacy with less toxicity, because it is produced and modified by the host's own cells. The observation that a greater percentage of neurons were spared from axotomy-induced death than the percentage transduced with Adv.RSV-nf demonstrates that it is not necessary to modify all neurons genetically to achieve a significant therapeutic effect.

Note added in proof: While this paper was in review two papers were published reporting similar neuroprotective effects on facial neuron survival after axotomy using adenoviral vectors carrying genes for BDNF, CNTF, and GDNF [Gimenez y Ribotta M, Revah F, Pradier L, Loquet I, Mallet J, Privat A (1997) Prevention of motoneuron death by adenovirus-mediated neurotrophic factors. J. Neurosci Res 48:281-285; and Gravel C, Gotz R, Lorrain A, Sendtner M (1997) Adenoviral gene transfer of ciliary neurotrophic factor and brain-derived neurotrophic factor leads to longterm survival of axotomized motor neurons. Nat Med 3:765-770].

\section{REFERENCES}

Akli S, Caillaud C, Vigne E, Stratford-Perricaudet LD, Poenaru L, Perricaudet M, Kahn A, Peschanski MR (1993) Transfer of a foreign gene into the brain using adenovirus vectors. Nat Genet 3:224-228.

Baumgartner BJ, Barnes Jr EM (1994) Analysis of neuronal mRNA levels by quantitative reverse transcriptase-polymerase chain reaction. In: Neuroscience protocols, Module 4, Sec 20 (Wouterlood FG, ed), pp 1-13. Amsterdam: Elsevier Science.

Chomczynski P, Sacchi N (1987) Single-step method of RNA isolation by acid guanidinium thiocyanate-phenol-chloroform extraction. Anal Biochem 162:156-159.

Davidson BL, Allen ED, Kozarsky KF, Wilson JM, Roessler BJ (1993) A model system for in vivo gene transfer into the central nervous system using an adenoviral vector. Nat Genet 3:219-223.

Davies AM (1989) Neurotrophic factor bioassay using dissociated neurons. In: Nerve growth factors (Rush RA, ed), pp 95-109. New York: Wiley.

Eaton MJ, Whittemore SR (1996) Autocrine BDNF secretion enhances the survival and serotonergic differentiation of raphe neuronal precursor cells grafted into the adult rat CNS. Exp Neurol 140:105-114.

Fang B, Eisensmith RC, Li XHC, Finegold MJ, Shedlovsky A, Dove W, Woo SLC (1994) Gene therapy for phenylketonuria: phenotypic correction in a genetically deficient mouse model by adenovirus-mediated hepatic gene transfer. Gene Ther 1:247-254.
Finiels F, Gimenez y Ribotta M, Barkats M, Samolyk M, Robert J, Privat A, Revah F, Mallet J (1995) Specific and efficient gene transfer strategy offers new potentialities for the treatment of motor neurone disease. NeuroReport 7:373-378.

Friedman B, Kleinfeld D, Ip NY, Verge VMK, Moulton R, Boland P, Zlotchenko E, Lindsay RM, Liu L (1995) BDNF and NT-4/5 exert neurotrophic influences on injured adult spinal motor neurons. J Neurosci 15:1044-1056.

Geschwind MD, Kessler JA, Geller AI, Federoff HJ (1994) Transfer of the nerve growth factor gene into cell lines and cultured neurons using a defective herpes simplex virus vector. Transfer of NGF gene into cells by a HSV-1 vector. Mol Brain Res 24:327-335.

Ghadge GD, Roos RP, Kang UJ, Wollmann R, Fishman PS, Kalynych AM, Barr E, Leiden JM (1995) CNS gene delivery by retrograde transport of recombinant replication-defective adenoviruses. Gene Ther 2:132-137.

Graham F, Prevec L (1991) Manipulation of adenovirus vectors. In: Methods in molecular biology: gene transfer and expression protocols (Murray EJ, ed), pp 109-128. Clifton, NJ: Humana.

Henderson CE, Phillips HS, Pollock RA, Davies AM, Lemeulle C, Armanini M, Simmons L, Moffet B, Vandlen RA, Koliatsos VE, Rosenthal A (1994) GDNF: a potent survival factor for motoneurons present in peripheral nerve and muscle. Science 266:1062-1064.

Kato AC, Lindsay RM (1994) Overlapping and additive effects of neurotrophins and CNTF on cultured human spinal cord neurons. Exp Neurol 130:196-201.

Koliatsos VE, Clatterbuck RE, Winslow JW, Cayouette MH, Price DL (1993) Evidence that brain-derived neurotrophic factor is a trophic factor for motor neurons in vivo. Neuron 10:359-367.

Laemmli UK (1970) Cleavage of structural proteins during the assembly of the head of bacteriophage T4. Nature 227:680-685.

Le Gal La Salle G, Robert JJ, Berrard S, Ridoux V, Stratford-Perricaudet LD, Perricaudet M, Mallet J (1993) An adenovirus vector for gene transfer into neurons and glia in the brain. Science 259:988-990.

Li L, Wu W, Lin LF, Lei M, Oppenheim RW, Houenou LJ (1995) Rescue of adult mouse motoneurons from injury-induced cell death by glial cell line-derived neurotrophic factor. Proc Natl Acad Sci USA 92:9771-9775.

Lin LH, Doherty DH, Lile JD, Bektesh S, Collins F (1993) GDNF: a glial cell line-derived neurotrophic factor for midbrain dopaminergic neurons. Science 260:1130-1132.

Lindsay RM, Rohrer H (1985) Placodal sensory neurons in culture: nodose ganglion neurons are unresponsive to NGF, lack NGF receptors but are supported by a liver-derived neurotrophic factor. Dev Biol 112:30-48.

Neve RL (1993) Adenovirus vectors enter the brain. Trends Neurosci 16:251-253.

Rabinovsky ED, Smith GM, Browder DP, Shine HD, McManaman JL (1992) Peripheral nerve injury down-regulates CNTF expression in adult rat sciatic nerves. J Neurosci Res 31:188-192.

Schecterson LC, Bothwell M (1992) Novel roles for neurotrophins are suggested by BDNF and NT-3 mRNA expression in developing neurons. Neuron 9:449-463.

Sendtner M, Kreutzberg GW, Thoenen H (1990) Ciliary neurotrophic factor prevents the degeneration of motor neurons after axotomy. Nature 345:440-441.

Sendtner M, Holtmann B, Kolbeck R, Thoenen H, Barde YA (1992) Brain-derived neurotrophic factor prevents the death of motoneurons in newborn rats after nerve section. Nature 360:757-759.

Smith GM, Rabinovsky ED, McManaman JL, Shine HD (1993) Temporal and spatial expression of ciliary neurotrophic factor after peripheral nerve injury. Exp Neurol 121:239-247.

Springer JE (1993) Experimental evidence for growth factor treatment and function in certain neurological disorders. Exp Neurol 124:2-4.

Towbin H, Staehelin T, Gordon J (1979) Electrophoretic transfer of proteins from polyacrylamide gels to nitrocellulose sheets: procedure and some applications. Proc Natl Acad Sci USA 76:4350-4354.

Yan Q, Elliott J, Snider WD (1992) Brain-derived neurotrophic factor rescues spinal motor neurons from axotomy-induced cell death. Nature 360:753-755.

Zhou XF, Zettler C, Rush RA (1994) An improved procedure for the immunohistochemical localization of nerve growth factor-like immunoreactivity. J Neurosci Methods 54:95-102. 